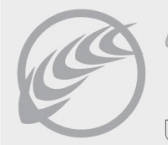

\title{
Exposure Assessment of Trans-Fatty Acids through Consumption of Sour Cream in Yerevan
}

\author{
D.A. Pipoyan, M.R. Beglaryan, S.A. Stepanyan \\ Center for Ecological-Noosphere Studies, NAS RA \\ david.pipoyan@cens.am, meline.beglaryan@cens.am, seda.stepanyan@cens.am
}

\section{A R T I CLE IN FO}

\section{Keywords:}

sour cream,

daily consumption,

trans-fatty acids,

total energy,

daily intake

\begin{abstract}
A B S T RA C T
The aim of the study is to assess the content of trans-fatty acids (TFA) present in the sour cream produced in the RA and conduct a dietary exposure assessment. Data on sour cream consumption has been gathered through food frequency questionnaire (FFQ). TFA contents in sour cream samples were determined using the method of gas chromatography. Daily intake of TFA through sour cream consumption has been estimated. TFA daily intake (E \%) accounted for $0.03 \%, 0.185 \%$ and $0.457 \%$ of total energy intake (kcal) for sour cream consumption Cluster 1, 2 and 3, respectively. It was discovered that TFA daily intake through sour cream consumption does not exceed the recommended threshold value ( $\leq 1 \mathrm{E} \%)$.
\end{abstract}

\section{Introduction}

Trans-fatty acid (TFA) is an unsaturated fatty acid produced industrially through partial hydrogenation of liquid vegetable oils. TFA may also occur naturally in the stomach of ruminants as a result of anaerobic bacterial fermentation (Lichtenstein, 2016, Longhi, 2019). According to many investigations, there is a link between TFAs and various diseases (particularly breast and large intestine cancer, nervous system disorders, obesity, allergy) (Hammad, et al., 2016, Nishida \& Uauy, 2009, WHO, 2019). Therefore, in recent years, many countries have implemented polices towards limiting and reducing TFA contents in human diet. Every year, it becomes more widespread that dietary intakes of TFA should be as low as possible (ALAP). Many countries have implemented effective approaches to regulate TFA amounts in foods and impose mandatory labeling of products (EFSA, 2018, WHO, 2019).

Armenia is a member of Eurasian Economic Union (EEAU) and follows its Customs Union technical regulations for fat-and-oil products (CU TR 024/2011). The latter defines acceptable contents for TFAs and the requirement for mandatory labeling only for fat-and-oil products. However, there are no requirements for either TFA contents or labeling for other processed products rather than fats and oils. Therefore, it is important to investigate the presence of TFA not only in fat and oil products, but also in products for which the latter are 
used as raw materials. Besides, foods that contain milk fat replacers (vegetable oils) and are consumed widely in Armenia during the recent years, can also be risky. Dairy products, sour cream, in particularly, are one of these food types. Recently, in Armenia, the production of sour cream has increased drastically. Compared to 2018, sour cream production has increased by $27.5 \%$ in 2020 , amounting to 4457 tons (SC, 2020a).

The above mentioned facts ascertain that in order to discover potential risks and implement preventive measures, it is important to implement investigations related to TFA content and its daily intake. Currently, there is no sciencebased data regarding TFA content of sour cream produced in Armenia. Hence, the present study aims to assess TFA content and its dietary exposure through the consumption of sour cream.

The investigation has been carried out through the funding of the Ministry of Education, Science, Culture and Sports of the RA, in the framework of 19YR-4A037 scientific theme.

\section{Materials and methods}

\section{Sour cream sampling and determination of TFA content}

Sour cream has been sampled from different selling points of Yerevan. In total, 11 of the most widely consumed sour cream samples have been collected (Table 1).

Table 1. Data on the investigated sour cream samples*

\begin{tabular}{|c|c|}
\hline Sample numbers & Producer \\
\hline $\mathrm{SC}_{-} 1$ & "Prostokvashino" \\
\hline $\mathrm{SC} \_2$ & "Biokat" LLC \\
\hline $\mathrm{SC} \_3$ & "Stepanavan Farm" \\
\hline $\mathrm{SC}_{-} 4$ & “Chanakh” LLC \\
\hline $\mathrm{SC} \_5$ & "Dustr Marianna" LLC \\
\hline SC_6 & “Ashtarak Kat” CJSC \\
\hline $\mathrm{SC}_{-} 7$ & "Tamara \& Ani” LLC \\
\hline SC_8 & “Tamara” LLC \\
\hline $\mathrm{SC} 99$ & "Bandivan" LLC \\
\hline $\mathrm{SC} \_10$ & "Marila” LLC \\
\hline SC_11 & "Bonilat" LLC \\
\hline
\end{tabular}

*Composed by the authors.
Determination of TFA contents was performed by an independent laboratory of "Standard Dialog" LLC accredited by ISO/IEC 17025:2005 standards. Investigations were carried out using gas chromatography accroding to GOST 31663-2012 and GOST 32261-2013 standards defined for determination of trans-fatty acid methyl esters (GOST 31663-2012, GOST 32261-2013). This method is designed to evaluate the level of trans-isomers as formed during hydrogenation of vegetable oils or fats.

\section{Sour cream consumption and statistical data analysis}

Sour cream consumption data has been collected using food frequency questionnaire (FFQ). Surveys have been conducted in 2020 by the Informational-Analytical Center for Risk Assessment of Food Chain of Center for Ecological Noosphere Studies of the RA. Four hundred residents of Yerevan city, aged from 18 to 65 took part in the survey. Statistical analysis of data was performed by SPSS software (SPSS Inc., version 22.0).

To get a normal distribution of consumption values, K-means Cluster analysis method was applied. This method was shown to be effective especially for the analysis of dietary patterns in a large population using FFQs. Moreover, a Cluster analysis method allows revealing homogenous groups of consumers and computes average consumption values more precisely (Ares, 2014).

\section{Daily Intake of TFA}

By combining data of TFA content and sour cream consumption, daily intake (DI) of TFA ( $\mathrm{g}$ /day) is calculated through the following equation:

$$
D I=C \times I R,
$$

where $C$ is the mean content of TFA in all studied sour cream products ( $\mathrm{g}$ in $100 \mathrm{~g}$ ), IR is the daily consumption of sour cream ( $\mathrm{g} /$ day) for each Cluster.

Daily intake of TFA has been represented as a percentage of total energy using the following equation (Liu, et al., 2015):

$$
E \%=\frac{D l \times 9}{D E} \times 100,
$$

where $E \%$ is the daily TFA intake as the percentage of total energy. $D l$ is the TFA intake per day (g/day). The energy transfer index of TFA is $9 \mathrm{kcal} / \mathrm{g}$. $D E$ is the total dietary energy intake (kcal). The average resident in Yerevan city consumes approximately $2047 \mathrm{kcal} /$ day (SC, 2020b). 


\section{Results and discussions}

\section{Content of TFAs in sour cream}

Fat content in sour cream samples ranged from 17-20\%. Based on these data, TFA content has been calculated in 100 grams of sour cream. According to the results, TFA content ranged from 0.0446 grams to 1.2414 grams. The average TFA content in 100 grams of sour cream was equal to 0.4711 grams (Table 2).

Table 2. The contents of TFA in sour cream*

\begin{tabular}{|c|c|c|c|}
\hline $\begin{array}{c}\text { Sample } \\
\text { number }\end{array}$ & $\begin{array}{c}\text { Content of } \\
\text { fat in sour } \\
\text { cream } \\
\mathbf{( \% )}\end{array}$ & $\begin{array}{c}\text { TFA content } \\
\text { detected in } \\
\text { sour cream } \\
\mathbf{( \% )}\end{array}$ & $\begin{array}{c}\text { TFA content } \\
\text { in sour cream } \\
\mathbf{( g / 1 0 0} \mathbf{g})\end{array}$ \\
\hline SC_1 & 17 & 3.074 & 0.5225 \\
\hline SC_2 & 18 & 4.549 & 0.8188 \\
\hline SC_3 & 18 & 0.339 & 0.0610 \\
\hline SC_4 & 18 & 2.654 & 0.4777 \\
\hline SC_5 & 20 & 0.223 & 0.0446 \\
\hline SC_6 & 25 & 1.191 & 0.2977 \\
\hline SC_7 & 18 & 1.955 & 0.3519 \\
\hline SC_8 & 20 & 6.207 & 1.2414 \\
\hline SC_9 & 18 & 1.784 & 0.3211 \\
\hline SC_10 & 18 & 2.505 & 0.4509 \\
\hline SC_11 & 20 & 2.987 & 0.5974 \\
\hline Average content of TFA in sour cream & $\mathbf{0 . 4 7 1 1}$ \\
\hline samples (g/100 g) & & & \\
\hline
\end{tabular}

*Composed by the authors.

According to a study conducted in Lithuania, in 2012, transfatty acids have been detected in different sour cream samples (with 30\% fat content). The average TFA content was equal to $9.4 \%$ (based on fat content) which is approximately 4 times higher than the average TFA content (2.4\%) determined in this study (Mieželienè, et al., 2012). Based on another investigation, sour cream samples collected in 2020, from 3 different sour cream producers of Hungary, contained various fats, including TFAs. The average content of TFA was estimated to be $2.66 \mathrm{~g} / 100 \mathrm{~g}$ (Izsó, et al., 2020), which is approximately 5 times higher than the average TFA content $(0.4711 \mathrm{~g} / 100 \mathrm{~g})$ determined in this study.

There is no regulation regarding TFA content in sour cream sold in Armenia. Therefore, in order to understand whether the detected TFA contents represent a risk for the population, it is crucial to estimate the daily intake of TFA through sour cream consumption.

\section{Sour cream consumption}

The results of K-means Cluster analysis revealed 3 Cluster groups for sour cream consumption. In case of Cluster 1, 2 and 3, the average daily sour cream consumption was equal to $14.64 \mathrm{~g} /$ day, $89.13 \mathrm{~g} /$ day and $220.8 \mathrm{~g} /$ day, respectively (Figure 1).

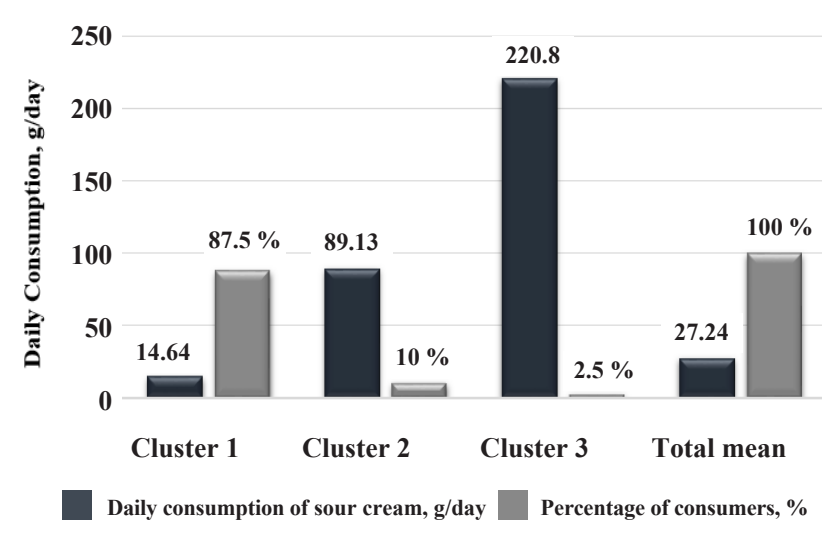

Figure 1. Daily consumption of sour cream (composed by the authors).

Cluster 1 is characterized with the lowest consumption value, but includes the majority of sour cream consumers (87.5\%), whereas Cluster 3 is characterized with the highest consumption value, but includes only $2.5 \%$ of consumers. Cluster 2 includes $10 \%$ of the consumers.

\section{DI of TFA}

To regulate TFA content in the diet, in many countries (such as Germany, Austria, Sweden, Belgium, Netherlands, Spain, Australia, Canada) it is required that the average daily intake of trans-fats should not exceed $1 \%$ of daily total energy $(\leq 1 \mathrm{E} \%)$. The latter is the threshold value recommended by the World Health Organization (WHO, 2019). However, in some countries, such as France and United Kingdom, the required threshold for TFA is less than $2 \%$ of daily total energy ( $\leq 2 \mathrm{E} \%$ ) (EFSA, 2018).

In order to carry out a dietary exposure assessment, daily intake was calculated (Figures 2 and 3) and compared with WHO's recommended level of less than $2.2 \mathrm{~g} /$ day for total TFA intake, which is equal to less than $1 \%$ of total energy intake (WHO, 2019). In case of the largest Cluster of sour cream consumption, daily intake of TFA exceeds the values for Cluster 1 and 2 by 15 and 2.5 times, respectively. 


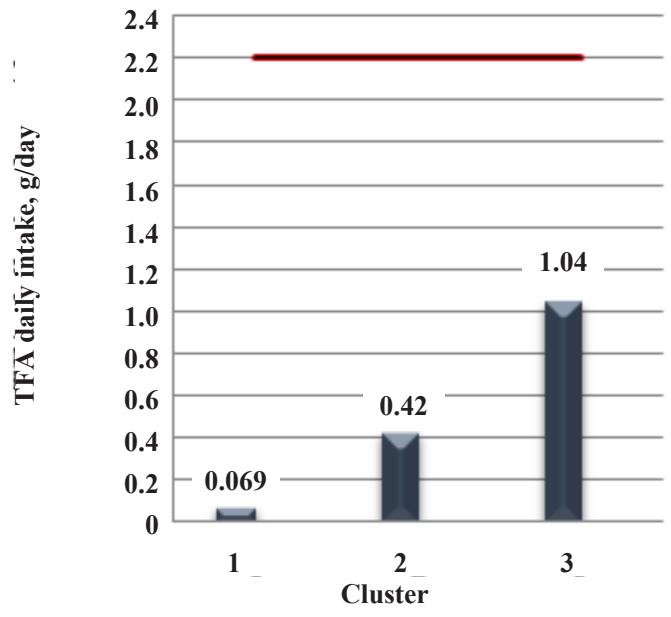

Figure 2. Daily intake of TFA (g/day) for each Cluster (composed by the authors).

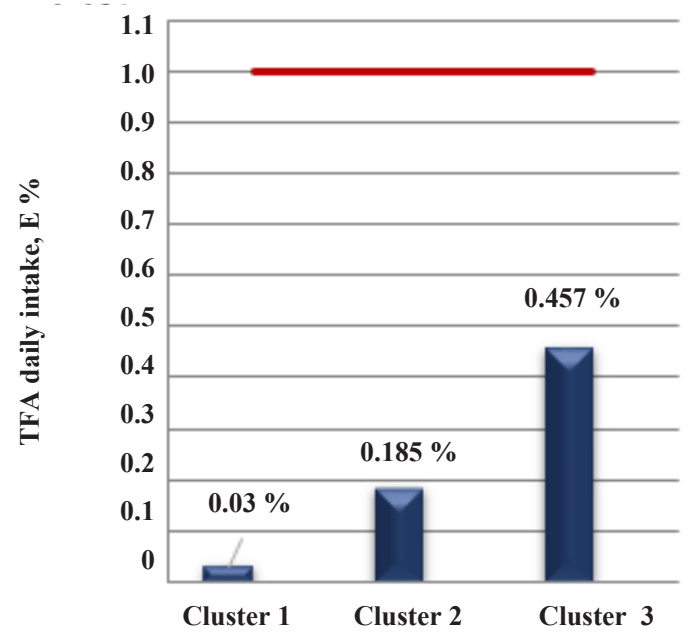

Figure 3. Daily intake of TFA as a percentage of total energy (composed by the authors).

As Figure 3 indicates, daily intake of TFA for sour cream consumption in Clusters 1, 2 and 3 accounts for $0.03 \%, 0.185 \%$ and $0.457 \%$ of the total energy intake, respectively. These values do not exceed the WHO's recommended limit $(\leq 1 \mathrm{E} \%)$, however, in case of only sour cream consumption, daily intake of TFA for Cluster 3 accounts for approximately $45 \%$ of the threshold value. It should be noted, that according to another investigation conducted in Yerevan city, in 2020, TFAs have been found in ice-cream samples. The daily intake of TFA (calculated for summer season) accounted for $0.041 \%$ of the total energy intake (Pipoyan, et al., 2020).

\section{Conclusion}

The results of the current study indicate that sour cream samples sold in Armenia, contain trans-fatty acids. Although, daily intake values of TFA do not exceed the WHO's recommended limit of $1 \%$ of total energy intake, in case of Cluster 3, TFA DI accounts for around $45 \%$ of the threshold value. Considering the fact, that there can be other products in the market that contain TFA, it is crucial to conduct continuous and large-scale dietary exposure assessment studies.

\section{References}

1. Ares, G. (2014). Cluster Analysis: Application in Food Science and Technology in Mathematical and Statistical Methods in Food Science and Technology. (G. A. D. Granato, Ed.) West Sussex.

2. CU TR 024/2011. CU Commission Decision No.883 of December 9, 2011 on Adoption of the Technical Regulation on Fat and Oil Products.

3. EFSA. (2018). Scientific and Technical Assistance on Trans-Fatty Acids. EFSA Supporting Publications, 15(6), 1433E. Available at: https://efsa.onlinelibrary. wiley.com/doi/epdf/10.2903/sp.efsa.2018.EN-1433 (accessed on 20.11.2020).

4. GOST 31663-2012. Vegetable Oils and Animal Fats. Determination of Methyl Esters of Fatty Acids by Gas Chromatography Method.

5. GOST 32261-2013. Butter. Specifications. Technical Conditions.

6. Hammad, S., Pu, S., Jones, P.J. (2016). Current Evidence Supporting the Link between Dietary Fatty Acids and Cardiovascular Disease. Lipids, 51(5), - pp. 507-517.

7. Izsó, T., Kasza, G., Somogy1, L. (2020). Differences Between Fat-Related Characteristics of Sour Cream and Sour Cream Analogues. Acta Alimentaria, 49(4), - pp. 390-397.

8. Lichtenstein, A.H. (2016). Fatty Acids: TransFatty Acids. Encyclopedia of Food and Health, - pp. 645-648.

9. Liu, A.D., LI, J.W., Liu, Z.P., Zhou, P.P., Mao, W.F., Ning, L.I., Zhang, L. (2015). Trans-Fatty Acid Levels in Foods and Intakes among Population Aged 3 Years and above in Beijing and Guangzhou Cities, China. Biomedical and Environmental Sciences, 28(7), - pp. 477-485. 
10. LLC accredited by ISO/IEC 17025:2005 https:// citalogistics.com/our-services/coal-testing-inspection/iso170252005-accreditation/ (accessed on 18.11.2020)

11. Longhi, R. (2019). Trans-Fatty Acid in the Liver and Central Nervous System. In Dietary Interventions in Liver Disease, Academic Press, - pp. 275-286.

12. Mieželienè, A., Alenčikienè, G., Zaborskienė, G. Garmiené, G. (2012). Effect of Fat Origin on Sensory and Physicochemical Characteristics of Sour Cream. Milchwissenschaft. Milk Science International. Kempten: AVA Agrar-Verlag Allgäu GmbH, - vol. 67, no. 1.

13. Nishida, C., Uauy, R. (2009). WHO Scientific Update on Health Consequences of Trans Fatty Acids: Introduction.

14. Pipoyan, D., Beglaryan, M., Stepanyan, S., Gharibyan,
G. (2020). Dietary Exposure Assessment of TransFatty Acids through Consumption of Ice-Cream in Yerevan, Armenia. Agriscience and Technology, 70(2), - pp. 92-96.

15. SC (2020a). Statistical Committee of the RA: Production. Available at: https://www.armstat.am/file/ article/sv_08_20a_121.pdf (accessed on 20.11.2020).

16. SC (2020b). Statistical Committee of the RA: Food Utilization. Available at: https://www.armstat.am/file/ article/f_sec 12020 6.pdf (accessed on 20.11.2020).

17. WHO (2019). Countdown to 2023: WHO Report on Global Trans-Fat Elimination. Available at: https://apps.who.int/iris/bitstream/ handle/10665/331300/9789241516440-eng.pdf (accessed on 20.11.2020).

This work was supported by the RA MES Science Committee, in the frames of the research project № 19YR-4A037. 